\title{
What are the effects of drug treatments for panic disorder?
}

This article is part of a new initiative in Evidence-based Mental Health, namely the serialisation of chapters of Clinical Evidence (a summary of the best available evidence on common clinical interventions updated regularly by the BMJ Publishing Group). This article is based on material presented in:Kumar S, Oakley-Browne M. Panic disorder. Clinical Evidence 2002; 8: 1003-9. For this review, Clinical Evidence searched and appraised material published until May 2002. Studies with follow up periods of less than 6 months were excluded.

A panic attack is a period in which there is sudden onset of intense apprehension, fearfulness or terror, often associated with feelings of impending doom. Panic disorder occurs when there are recurrent, unpredictable attacks followed by at least 1 month of persistent concern about having another panic attack; worry about the possible implications or consequences of the panic attacks, or a significant behavioural change related to the attacks. ${ }^{1}$ The term "panic disorder" excludes panic attacks attributable to the direct physiological effects of a general medical condition, substance or another mental disorder. Panic disorder is sometimes categorised as "with" or "without agoraphobia." Alternative categorisations focus on phobic anxiety disorders and specify agoraphobia with or without panic disorder. ${ }^{2}$

\section{Prevalence}

Panic disorder often starts around 20 years of age (between late adolescence and the mid-30s). ${ }^{3}$ Lifetime prevalence is $1-3 \%$, and panic disorder is more common in women than in men. ${ }^{4}$ An Australian community study found 1 month prevalence rates for panic disorder (with or without agoraphobia) of $0.4 \%$ using International Classification of Diseases (ICD)-10 diagnostic criteria and of $0.5 \%$ using Diagnostic and Statistical Manual (DSM)-IV diagnostic criteria. ${ }^{5}$

\section{Risk factors}

Stressful life events tend to precede the onset of panic disorder, ${ }^{6} 7$ although a negative interpretation of these events in addition to their occurrence has been suggested as an important causal factor. ${ }^{8}$ Panic disorder is associated with major depression, ${ }^{9}$ social phobia, generalised anxiety disorder, obsessive compulsive disorder, ${ }^{10}$ and a substantial risk of drug and alcohol abuse. ${ }^{11}$ It is also associated with avoidant, histrionic and dependent personality disorders. ${ }^{10}$

\section{Prognosis}

The severity of symptoms in people with panic disorder fluctuates considerably, with periods of no attacks, or only mild attacks with few symptoms, being common. There is often a long delay between the initial onset of symptoms and presentation for treatment. Recurrent attacks may continue for several years, especially if associated with agoraphobia. Reduced social or occupational functioning varies among people with panic disorder and is worse in people with associated agoraphobia. Panic disorder is also associated with an increased rate of attempted, but unsuccessful, suicide. ${ }^{12}$

\section{Treatment aims}

To reduce the severity and frequency of panic attacks, phobic avoidance, and anticipatory anxiety; to improve social and occupational functioning, with minimal adverse effects of treatment.

\section{Key messages}

\begin{tabular}{lc}
$\begin{array}{l}\text { Evidence that treatment is } \\
\text { beneficial }\end{array}$ & $\begin{array}{c}\text { Trade off between benefits } \\
\text { and harms }\end{array}$ \\
$\begin{array}{l}\text { tricyclic antidepressants } \\
\text { (imipramine) }\end{array}$ & benzodiazepines \\
\hline $\begin{array}{l}\text { selective serotonin reuptake } \\
\text { inhibitors }\end{array}$ & Unknown effectiveness \\
\hline & monoamine oxidase inhibitors \\
\hline
\end{tabular}

\section{Benzodiazepines}

One systematic review and one additional randomised trial have found that alprazolam versus placebo significantly reduces the number of panic attacks and improves symptoms. However, benzodiazepines are associated with a wide range of adverse effects, both during their use and after treatment has been withdrawn.

\section{Buspirone}

Randomised controlled trials found insufficient evidence on the effects of buspirone versus placebo.

\section{Monoamine oxidase inhibitors}

We found no randomised controlled trials on the effects of monoamine oxidase inhibitors.

\section{Selective serotonin reuptake inhibitors}

Two systematic reviews and one additional randomised controlled trial have found that selective serotonin reuptake inhibitors versus placebo improve symptoms in panic disorder. One randomised controlled trial found that discontinuation of sertraline in people with a good response significantly increased exacerbation of symptoms.

\section{Tricyclic antidepressants (imipramine)}

One systematic review and subsequent randomised controlled trials have found that imipramine versus placebo significantly improves symptoms. One randomised controlled trial found that imipramine significantly reduced relapse rates over 12 months. 


\section{Outcomes}

Measures of panic attacks, agoraphobia, and associated disability (self reported and clinician rated, before and after treatment and longer term) using general scales or specific scales for panic disorder (eg the panic and agoraphobia scale, the mobility inventory for agoraphobia).

\section{What are the effects of tricyclic antidepressants for panic disorder?}

One systematic review and subsequent randomised controlled trials have found that imipramine versus placebo improves symptoms in people with panic disorder. One randomised controlled trial found that imipramine reduced relapse rates in people with panic disorder.

\section{BENEFITS}

We found one systematic review, ${ }^{13}$ one additional randomised controlled trial, ${ }^{14}$ and two subsequent randomised controlled trials. ${ }^{15} 16$ The systematic review (search date not stated, 27 randomised controlled trials, 2348 people) compared imipramine, selective serotonin reuptake inhibitors (paroxetine, fluvoxamine, zimelidine and clomipramine), and alprazolam versus placebo and versus each other. ${ }^{13}$ It found that imipramine versus placebo significantly increased the number of people judged to have improved $(\mathrm{p}<0.0001)$.

The additional randomised controlled trial (181 people with panic disorder with or without agoraphobia) compared 3 treatments: oral imipramine (maximum dose $225 \mathrm{mg}$ ); oral alprazolam (maximum dose $10 \mathrm{mg}$ ); and placebo. ${ }^{14}$ It found that imipramine versus placebo reduced the number of panic attacks after 8 months (results presented graphically, significance not calculated).

The first subsequent randomised controlled trial (56 adults with panic disorder and agoraphobia in stable remission after 24 weeks treatment with oral imipramine) comparing oral imipramine $(2.25 \mathrm{mg} / \mathrm{kg}$ daily) versus placebo found that significantly fewer people taking imipramine relapsed after 12 months $(1 / 29$ [3\%] with imipramine $v 10 / 27$ [37\%] with placebo; RR $0.09,95 \%$ CI 0.01 to 0.68 ; NNT 5, 95\% CI 3 to 14). ${ }^{16}$

The second subsequent randomised controlled trial (312 people) compared five groups: oral imipramine (maximum dose $300 \mathrm{mg}$ daily); cognitive behavioural therapy; placebo; cognitive behavioural therapy plus oral imipramine (maximum dose $300 \mathrm{mg}$ daily); and cognitive behavioural therapy plus placebo. ${ }^{15}$ It found that imipramine versus placebo significantly increased the number of people judged to have responded using the panic disorder severity scale after 6 months $(38 \%$ response rate with imipramine $v 13 \%$ response rate with placebo; absolute numbers not provided; $\mathrm{p}=0.02$ ).

\section{HARMS}

Adverse effects associated with imipramine treatment included blurred vision, tachycardia, palpitations, blood pressure changes, insomnia, nervousness, malaise, dizziness, headache, nausea, vomiting, and reduced appetite. ${ }^{14}{ }^{17}$

\section{COMMENT}

The review included clomipramine as a serotonin reuptake inhibitor. This drug is also often described as a tricyclic antidepressant. ${ }^{13}$ The review used improvement as an outcome measure without a clear definition of this term. In the additional randomised controlled trial and the second subsequent randomised controlled trial, flexible dosing was used according to tolerance and therapeutic need. ${ }^{14}{ }^{15}$ In the subsequent randomised controlled trial comparing imipramine versus placebo, relapse rate was not clearly defined. ${ }^{16}$
What are the effects of selective serotonin reuptake inhibitors (SSRI) for panic disorder?

Two systematic reviews and one additional randomised controlled trial have found that selective serotonin reuptake inhibitors versus placebo improve symptoms in panic disorder. One randomised controlled trial found that discontinuation of sertraline in people with a good response significantly increased exacerbation of symptoms.

\section{BENEFITS}

We found two systematic reviews, ${ }^{13}{ }^{18}$ one additional randomised controlled trial, ${ }^{20}$ and one subsequent randomised controlled trial. ${ }^{19}$ The first systematic review (search date not stated, 27 randomised controlled trials, 2348 people) found that selective serotonin reuptake inhibitors (paroxetine, fluvoxamine, zimelidine and clomipramine) versus placebo significantly increased the number of people who improved $(\mathrm{p}<0.0001){ }^{13}$

The second systematic review (search date not stated, 12 randomised controlled trials, 1741 people) only reported combined results as an effect size against placebo (effect size 0.55), and did not report statistical significance. ${ }^{18}$

The additional randomised controlled trial (279 people) compared five groups: oral citalopram (10 or $15 \mathrm{mg}$ daily); oral citalopram (20 or $30 \mathrm{mg}$ daily); oral citalopram (40 or $60 \mathrm{mg}$ daily); oral clomipramine (60 or $90 \mathrm{mg}$ daily); and placebo. ${ }^{20} \mathrm{It}$ found that citalopram (at all doses) versus placebo significantly increased the number of people who responded (defined as no panic attacks and either no episodic increases in anxiety or only slight increases in anxiety precipitated by definite events or activities) after 12 months (citalopram 10 or $15 \mathrm{mg}$ daily $v$ placebo $\mathrm{p}=0.05$; citalopram 20 or $30 \mathrm{mg}$ daily $v$ placebo $\mathrm{p}=0.001$; citalopram 40 or $60 \mathrm{mg}$ daily $v$ placebo $\mathrm{p}=0.003$; results presented graphically).

The subsequent randomised controlled trial (182 people who had responded to open label sertraline for $52 \mathrm{wks}$ ) compared double blind placebo (discontinuation of sertraline) versus sertraline for 28 weeks. ${ }^{19}$ It found significantly more people on placebo had exacerbation of symptoms (33\% with placebo $v 13 \%$ with sertraline, $\mathrm{p}=0.005$; CI not available).

\section{HARMS}

The additional randomised controlled trial reported that harms associated with citalopram included headache, tremor, dry mouth, and somnolence. ${ }^{20}$

\section{COMMENT}

The first review included clomipramine as a selective serotonin reuptake inhibitor, although this drug is often described as a tricyclic antidepressant. ${ }^{13}$ In addition, the review used improvement as an outcome measure without clearly defining this term. In the additional randomised controlled trial, only just over half of people (28/54 [52\%]) completed the trial; analysis was by intention to treat and people who withdrew from the trial were counted as treatment failures..$^{20}$ The randomised controlled trial used flexible dosing according to tolerance and therapeutic need. Selective serotonin reuptake inhibitors can cause initial increased anxiety, which can exacerbate a tendency to focus on internal sensations and to avoid situations that trigger these sensations (catastrophise somatic sensations). Education about this event is likely to improve adherence with medication. The second systematic review found smaller randomised controlled trials were associated with larger effect sizes suggesting the possibility of publication bias. ${ }^{18}$ 
What are the effects of monoamine oxidase inhibitors for panic disorder?

We found no evidence on the effects of monoamine oxidase inhibitors in panic disorder.

We found no systematic review and no randomised controlled trials. We found no evidence of harms associated specifically with the use of monoamine oxidase inhibitors in the long term treatment of panic disorder. Our search strategy excluded studies with follow up of less than 6 months.

\section{What are the effects of buspirone for panic disorder?}

Two randomised controlled trials found insufficient evidence on the effects of buspirone in people with panic disorder.

\section{BENEFITS}

We found no systematic review but found two randomised controlled trials. ${ }^{21}{ }^{22}$ The first randomised controlled trial (48 people) compared oral buspirone (maximum $60 \mathrm{mg}$ daily) plus cognitive behavioural therapy versus placebo plus cognitive behavioural therapy for 16 weeks. ${ }^{21}$ It found that oral buspirone plus cognitive behavioural therapy significantly improved self rated panic and agoraphobia scores after 1 year (using a 90 point symptom scale where each symptom was graded from $0=$ not present to $4=$ severe; $\mathrm{p}=0.03$; absolute numbers not provided).

The second randomised controlled trial (41 people with panic disorder and agoraphobia) compared 16 weeks of oral buspirone (30 mg daily) plus cognitive behavioural therapy versus 16 weeks of placebo plus cognitive behavioural therapy. ${ }^{22}$ It found no significant difference in the number of people who had a reduction of at least $50 \%$ in their agoraphobic symptoms after 68 weeks (44\% with buspirone plus cognitive behavioural therapy $v 68 \%$ with placebo plus cognitive behavioural therapy; absolute numbers of people not provided).

\section{HARMS}

The randomised controlled trials did not report harms.

\section{COMMENT}

The first randomised controlled trial used a flexible dosing regimen with maximum dose adjustment according to tolerance and therapeutic need. ${ }^{21}$

\section{What are the effects of benzodiazepines for panic disorder?}

One systematic review and one additional randomised controlled trial have found that alprazolam reduces the numbers of panic attacks and improves symptoms in people with panic disorder. Benzodiazepines are associated with a wide range of adverse effects, both during their use and after treatment has been withdrawn.

\section{BENEFITS}

We found one systematic review (search date not stated, 27 randomised controlled trials, 2348 people), ${ }^{13}$ and one additional randomised controlled trial..$^{14}$ The review found that alprazolam versus placebo significantly increased the number of people judged to have improved $(\mathrm{p}<0.0001) .{ }^{13}$

The additional randomised controlled trial (181 people with panic disorder with or without agoraphobia) compared three treatments: oral alprazolam (maximum $10 \mathrm{mg}$ daily), oral imipramine (maximum $225 \mathrm{mg}$ daily), and placebo. ${ }^{14}$ It found that alprazolam versus placebo was associated with fewer panic attacks after 8 months (results presented graphically; significance not calculated).
HARMS

The systematic review did not report harms. ${ }^{13}$ Adverse effects associated with alprazolam include sedation, insomnia, memory lapses, nervousness, irritability, dry mouth, tremor, impaired coordination, constipation, urinary retention, altered libido, and altered appetite. ${ }^{14}$ We found one non-systematic review of the effects of benzodiazepines in anxiety disorder in people with a history of substance abuse or dependence. ${ }^{23}$ The review reported that the mortality of long term benzodiazepine users was no higher than matched controls. It reported that the most pronounced adverse effects followed sudden withdrawal and included tinnitus, paraesthesia, vision disturbance, depersonalisation, seizures, withdrawal psychosis, and persistent discontinuation syndrome.

\section{COMMENT}

The review used improvement as an outcome measure without clearly defining this term. ${ }^{13}$ The additional randomised controlled trial used flexible dosing according to tolerance and therapeutic need. ${ }^{14}$ Many randomised controlled trials of psychological and pharmacological treatments (even those not involving benzodiazepines) allowed people to receive small amounts of anxiolytic drugs during the study because benzodiazepine abuse is quite prevalent in people who suffer from panic disorder.

SHAILESH KUMAR Division of Psychiatry Auckland Medical School New Zealand

MARK OAKLEY BROWNE Professor of Rural Psychiatry Monash University Victoria, Australia

1 American Psychiatric Association. Diagnostic and statistical manual of mental disorders. 4th ed. Washington DC: American Psychiatric Association, 1994. 2 World Health Organization. The ICD-10 classification of mental and behavioural disorders. Geneva: World Health Organization, 1992.

3 Robins LN, Regier DA (eds). Psychiatric disorders in America:the epidemiologic catchment area study. New York: Free Press, 1991.

4 Weissman MM, Bland MB, Canino GJ, et al. The cross-national epidemiology of panic disorder. Arch Gen Psychiatry 1997; 54: 305-9.

5 Andrews G, Henderson S, Hall W. Prevalence, comorbidity, disability and service utilisation. Overview of the Australian National Mental Health Survey. Br J Psychiatry 2001; 178: 145-53.

6 Last CG, Barlow DH, O'Brien GT. Precipitants of agoraphobia: role of stressful life events. Psychol Rep 1984; 54: 567-70.

7 De Loof C, Zandbergen H, Lousberg $\mathrm{T}$ et al. The role of life events in the onset of panic disorder. Behav Res Ther 1989; 27: 461-3.

8 Rapee RM, Mattick RP, Murrell E. Impact of life events on subjects with panic disorder and on comparison subjects. Am J Psychiatry 1990; 147: p40-4.

9 Hirschfield RMA. Panic disorder: diagnosis, epidemiology and clinical course. J Clin Psychiatry 1996; 57: 3-8.

10 Andrews G, Creamer M, Crino R et al. The treatment of anxiety disorders. Cambridge: Cambridge University Press, 1994.

11 Page AC, Andrews G. Do specific anxiety disorders show specific drug problems? Aust N Z J Psychiatry 1996; 30: 410-4.

12 Gorman JM, Coplan JD. Comorbidity of depression and panic disorder. $J$ Clin Psychiatry 1996; 57: 34-41.

13 Boyer W. Serotonin uptake inhibitors are superior to imipramine and alprazolam in alleviating panic attacks: a meta-analysis. Int Clin Psychopharnacol 1995; 10: 45-9. Search date not stated; primary sources Medine, plementary statistical information

14 Curtis GC, Massana J, Udina C et al. Maintenance drug therapy of panic Curtis GC, Massana J, Udina C et al. Main
disorder.J Psychiatr Res 1993; 27: 127-42.

15 Barlow DH, Gorman J, Shear MK et al. Cognitive-behavioral therapy, imipramine, or their combination for panic disorder: a randomized controlled trial.JAMA 2000; 283: 2529-36.

16 Mavissakalian MR, Perel JM. Long-term maintenance and discontinuation of imipramine therapy in panic disorder with agoraphobia. Arch Gen Psychiatry 1999; 56: 821-7.

17 Cassano GB, Toni C, Petracca A et al. Adverse effects associated with the short-term treatment of panic disorder with imipramine, alprazolam or placebo. Eur Neuropsychopharmacol 1994; 4: 47-53.

18 Otto M, Tuby K, Gould R et al. An effect-size analysis of the relative efficacy and tolerability of serotonin selective reuptake inhibitors for panic primary sources Medline, Psychlit, and hand searched references. 
19 Rapaport M, Wolkow R, Rubin A et al. Sertraline treatment of panic disorder: results of a long term study. Acta Psych Scand 2001; 104: 289-98.

20 Lepola UM, Wade AG, Leinonen EV et al. A controlled, prospective, 1-year trial of citalopram in the treatment of panic disorder.J Cin Psychiatry 1998

21 Bouvard M, Mollard E, Guerin J et al. Study and course of the psychological profile in 77 patients expressing panic disorder with agoraphobia after cognitive behaviour therapy with or without buspirone. Psychother Psychosom 1997; 66: 27-32.

22 Cottraux J, Note ID, Cungi C et al. A controlled study of cognitive behaviour therapy with buspirone or placebo in panic disorder with agoraphobia. Br J Psychiatry 1995; 167: 635-41.

23 Posternak M, Mueller T. Assessing the risks and benefits of benzodiazepines for anxiety disorders in patients with a history of substance abuse or dependence. Am J Addict 2001; 10: 48-68.

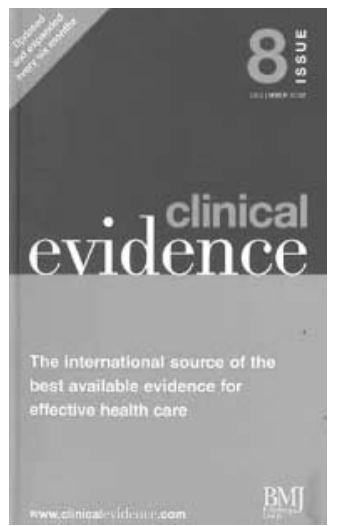

The full text of Clinical Evidence is updated monthly online at www.clinicalevidence.com. Information on subscriptions is available from CEsubscriptions@bmigroup.com,ph +44(0)20 73836270 (or, for North and South America, clinevid@pmds.com, ph 1-800-373-2897). Orders can also be made online.

\section{Difficulties developing evidence-based approaches in learning disabilities}

Around $2 \%$ of the population have a learning disability, categorised as 'mental retardation' in the ICD / DSM classification systems. Mental disorders are at least two to four times more prevalent in people with learning disability compared to the general population. ${ }^{1}$ Increasing numbers of people with learning disability access generic mental health services, due to philosophies of equity of access and normalisation. Mental health practitioners may address the problem of learning disabilities directly or help people deal with indirect outcomes, such as poor self concept or even self harm.

Learning disabilities affect both adults and children and can impact on a person's self esteem as well as their education and competency. People with learning disabilities may also have co-morbidities. Learning disability is manifested by two components: low cognitive ability and diminished social competence. Both factors are profoundly affected by social and cultural influences. Unlike other ICD 10 mental health disorders, it is difficult to specify detailed clinical diagnostic criteria for learning disability. After considering the cultural norms of a particular individual, mental health practitioners often estimate the intelligence quotient or mental age of the individual using specified levels of cognitive abilities (table). ${ }^{2}$

During the past 20 years, learning disability services have shifted from the hospital to specialist community services. ${ }^{3}$ Three key changes occurred with this shift: (1) the introduction of "care management;" (2) the creation of packages of social, educational and developmental care, and (3) allocating "physical care" to primary healthcare and "mental health care" to specialist health services. In the era of evidence-based medicine and clinical governance, each of these changes should be based on research evidence. ${ }^{4}$ Evidence-based strategies might lead to constructive change for people with learning disabilities, but evidence about effective interventions is limited and it may be difficult to extrapolate findings from research in the general population or in people with other mental difficulties. This lack of an evidencebase is of relevance to psychiatrists and psychologists practising in an era when "political correctness" and users' views may compete with evidence gained from more rigorous sources. This editorial examines why it is difficult to obtain rigorous research evidence on learning disability interventions.

\section{Research context}

As in many other fields of mental health, evidence in the field of learning disabilities is constrained by ethical concerns over capacity and consent. Large randomised trials are not always practical or acceptable given the nature of patients and interventions, yet there is a desire to incorporate more evidence into practice. ${ }^{5}$

There are several difficulties establishing an evidence-base in learning disabilities. These include transfer of knowledge from other disciplines, mental health co-morbidities, and service delivery practicalities. Other fields of mental health may encounter similar problems. The main difference in learning disabilities is that many disciplines work side by side, some with a historical grounding in empirical research and others with a more theoretical or anecdotal evidence-base.

Almost all evidence-based practice for learning disability has been transferred directly from adult psychiatry or mental health services, but this may not always be beneficial for people with learning disabilities. This population may have special needs. For example, a comparison of intensive and standard case management in severe mental illness found no outcome differences overall, ${ }^{6}$ but outcomes in people with borderline intelligence

Levels of cognitive abilities

\begin{tabular}{llll} 
Category & $\begin{array}{c}\text { Mental retardation } \\
\text { or learning } \\
\text { disability level }\end{array}$ & \multicolumn{1}{c}{ IQ range } & \multicolumn{1}{c}{$\begin{array}{c}\text { Mental age } \\
\text { (years) }\end{array}$} \\
F70 & Mild & 50 to 69 & 9 to under 12 \\
\hline F71 & Moderate & 35 to 49 & 6 to under 9 \\
\hline F72 & Severe & 20 to 34 & 3 to under 6 \\
\hline F73 & Profound & Less than 20 & Less than 3 \\
\hline
\end{tabular}


were significantly better after intensive case management. ${ }^{78} \mathrm{~A}$ similar trial compared assertive and standard community approaches in learning disability services, but the evaluators encountered several difficulties. They concluded that before learning disability services can be adequately evaluated, fundamental changes in attitudes towards research are needed in this field. ${ }^{9}$

Good evidence is definitely needed. Although most mental health workers agree that people with learning disabilities require specialist services, the nature and delivery of these services is far from clear. There have been many changes in recent years, including the expansion of community teams, reduction of hospital beds and development of specialist in-patient assessment services with controlled access to beds. These changes are by no means uniform - and we have little idea of their impact. ${ }^{10}$ We need common goals and outcomes to evaluate smaller locally accessible community services, but this is difficult in the complex and multidisciplinary field of learning disabilities. ${ }^{11}$ It is also difficult to determine the prevalence of mental disorders in people with learning disability. ${ }^{12}$ There is continuing debate as to whether behaviour disorder constitutes an environmental problem or a developmental disorder, for instance. ${ }^{13}$

All of these contextual factors make it difficult to find good evidence in the field of learning disabilities. There are also some practical problems with the quality of evidence in this field. The main practical difficulties involve ethical considerations, methodological problems, and service capacity. ${ }^{9}$

\section{Ethical dilemmas}

Randomisation is now better accepted in many mental health disciplines, but it is a major ethical issue in the field of learning disability. Many purchasers and service providers feel that it would be wrong to deprive a person of a "necessary" service. There may also be concerns that well established relationships between service users and carers would be wrongly compromised by randomising patients.

Campbell et al suggest that complex interventions can be evaluated using a systematic controlled trial methodology. ${ }^{14}{ }^{15}$ But some learning disabilities providers believe that services do not need to be evaluated or the most effective interventions trialled, because their value is self-evident. In our experience with the TACTILD trial, providers who did not take part "on ethical grounds" often said that denial of treatment was unethical, as ipso facto, it must be effective.

Informed consent may also be a problem, with participants being less competent to provide consent than the general population. This problem permeates many other mental health fields, such as work with youths and older people. However, among older people and youth, problems with informed consent may be limited to particular life stages. A person with learning disability will have difficulty providing informed consent throughout their lifetime. Similarly, relatives are often involved in learning disabilities services, either as the primary carer or as a significant contact. This means that, as in studies of young people, a second layer of informed consent is often needed.

\section{Methodology}

A wide range of disciplines are involved in the field of learning disability, some of which do not have a strong research tradition. There is a greater reliance on "expert opinion" than in some other mental health fields. There is also significant variation in resources and practice between teams. Even the definitions of different treatments may differ between practice teams. Services rarely define their practices operationally.
Another practical difficulty is the relatively long time period needed to detect changes in learning disabilities. Due to the low prevalence of certain conditions, sample sizes may also be considered small by traditional standards. The variety of disciplines involved in learning disability services and the variation and complexity of the services offered comprises a unique difficulty when implementing evidence-based medicine.

\section{Service capacity}

Currently, new learning disability services emerge only where there are strong supportive voices. This "expert opinion" is not necessarily based on high quality evidence. ${ }^{16}$ This is of increasing importance in the clinical governance era, where services with no scientific basis for their continuation may be withdrawn. Learning disabilities workers often acknowledge the need for high quality research, but resources are limited. It may not be justified to simply transfer the results of evidence-based practice from standard psychiatric services to learning disability services. It is likely to be more appropriate to develop evidence-based practices specifically for the learning disabled population, especially for those with a moderate or severe level of learning disability.

\section{Evidence needs}

Learning disability spans the boundaries between health and social care; specialist health and more general health services, and between child and adult services. As in other fields of mental health, an evidence-based philosophy is needed to develop and maintain high quality services. Questions of costeffectiveness and cost-benefit also need to be addressed. Adequate research funding is fundamental to this process, necessitating a change in service culture. The need and intention to evaluate must become the norm, not the exception. Without open questioning of current practice, learning disability services will be governed by opinion and product champions instead of a formal evidence-base.

Many mental health professionals have embraced evidencebased philosophies, but the field of learning disabilities has a little "catching up" to do. Promoting and developing rigorous academic research takes time. Despite the problems outlined here, the task is by no means impossible, provided there is ongoing multidisciplinary professional enthusiasm, cooperation and collaboration between users, carers, academic institutions, and health agencies.

PATRICIA C OLIVER, PhD DMS Faculty of Medicine, Imperial College London, United Kingdom

JACK PIACHAUD, FRCPsych MA BMBCH Hertfordshire Partnership NHS Trust Hertfordshire, United Kingdom

D JOHN DONE, PhD University of Hertfordshire Hatfield, United Kingdom

ADRIENNE REGAN, FRCPsych DCH MBBS Harrow Primary Care Trust Middlesex, United Kingdom

SHERVA E COORAY, FRCPsych DPM MBBS Brent Primary Care Trust London, United Kingdom

PETER J TYRER, MD FRCP FRCPsych FFPHM FMedSci Faculty of Medicine, Imperial College London, United Kingdom

1 Parson J, May J, Menoslascino FJ. The nature and incidence of mental illness in mentally retarded individuals. In: Menoslascino FJ, Tark JA (eds). Handbook of Mental Illness in the Mentally Retarded. New York: Plenum Publishers, 1984.

2 World Health Organisation. The ICD-10 classification of mental and behavioural disorders: diagnostic criteria for research. Switzerland: WHO, 1993. 
3 Farmer R, Rohde J, Sacks B. Changing Services for People with Learning Disabilities. London: Chapman and Hall, 1993.

Oyebode F, Brown N, Parry E. Clinical governance: application to psychiatry Psychiatric Bulletin 1999; 23: 7-10.

5 Fraser WI. Three decades after Penrose. British Journal of Psychiatry 2000; 176: $10-1$.

6 Burns T, Creed F, Fahy T et al. Intensive versus standard case management for severe psychotic illness: a randomised trial. Lancet 1999; 353: 2185-9.

Tyrer P, Hassiotis A, Ukoumunne $\mathrm{O}$ et al. Intensive case management for psychotic patients with borderline intelligence: UK 700 Group. Lance

8 Hassiotis A, Ukoumunne OC, Byford S et al. Intellectual functioning and outcome of patients with severe psychotic illness randomised to intensive case management: report from the UK700 case management trial. British Journal of Psychiatry 2001; 178: 166-71.

9 Oliver PC, Piachaud J, Done J et al. Difficulties in conducting a randomized controlled trial of health service interventions in intellectual disability: implications for evidence-based practice. Journal of Intellectual Disability Research 2002; 46: 340-5.

10 Bailey NM, Cooper SA. The current provision of specialist health services to people with learning disabilities in England and Wales. Journal of Intellectual Disability Research 1997; 41:52-9.

11 Department of Health. Signposts for Success in Commissioning and Providing Health Services for People with Learning Disabilities. London: UK Department of Health, 1998.

12 Russell O (ed). Seminars in the Psychiatry of Learning Disabilities. Scotland: Bell \& Bain Ltd and Royal College of Psychiatrists, 1997.

13 Emerson E, McGill P, Mansell J (eds). Severe Learning Disabilities and Challenging Behaviours - Designing High Quality Services. London: Chapman and Hall, 1994

14 Campbell M, Fitzpatrick R, Haines A et al. Framework for design and evaluation of complex interventions to improve health. BMJ 2000; 321 : $694-6$.

15 Prescott R.J, Gillespie WJ, Counsell CE et al. Factors that limit the number, quality, and progress of randomised trials. In: Black N, Brazier J, Fitzpatrick R et al (eds). Health Servies Research Methods: A Guide To Best Practice. London: BMJ Publishing Group, 1998: 86-97.

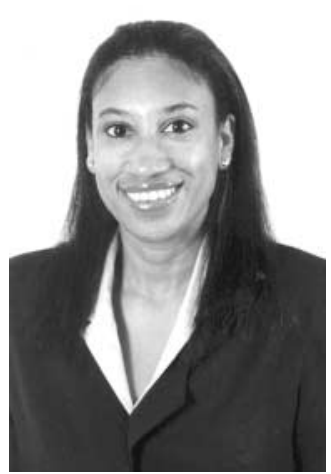

Correspondence to: Patricia Oliver, Department of Psychological Medicine, Faculty of Medicine, Imperial College,London, UK. poliver@ic.ac.uk.

16 Geddes JR, Harrison PJ. Closing the gap between research and practice. British Journal of Psychiatry 1997; 171: 220-5.

\section{ACKNOWLEDGEMENTS}

Some of the ideas in this piece are based on the article: Oliver PC, Piachaud J, Done J et al. Difficulties in conducting a randomized controlled trial of health service interventions in intellectual disability: implications for evidence-based practice. Journal of Intellectual Disability Research 2002; 46: 340-5. We thank the North Thames Region R \& D for original funding and Helen Bond, Senior Library Assistant, Hertfordshire Partnership NHS Trust, for her assistance throughout the TACTILD project. 